Review Article

\title{
Smooth Extubation and Smooth Emergence Techniques: A Narrative Review
}

\author{
Tiffany H. Wong $\mathbb{D}^{1},{ }^{1}$ Garret Weber $\mathbb{D}{ }^{1,2}$ and Apolonia E. Abramowicz $\mathbb{D}^{1,2}$ \\ ${ }^{1}$ New York Medical College, Valhalla, NY, USA \\ ${ }^{2}$ Department of Anesthesiology, Westchester Medical Center, Valhalla, NY, USA \\ Correspondence should be addressed to Tiffany H. Wong; twong7@student.nymc.edu
}

Received 28 August 2020; Revised 4 November 2020; Accepted 6 January 2021; Published 15 January 2021

Academic Editor: Ronald G. Pearl

Copyright (C) 2021 Tiffany H. Wong et al. This is an open access article distributed under the Creative Commons Attribution License, which permits unrestricted use, distribution, and reproduction in any medium, provided the original work is properly cited.

\begin{abstract}
There is a paucity of literature on extubation technique and a lack of consensus regarding the definition of smooth extubation. This narrative review paper defines an ideal extubation, otherwise known as a "smooth extubation," reviews perioperative criteria for extubation and risks and adverse events related to extubation, and explores various perioperative techniques that can be used to achieve a smooth extubation while caring for an uncomplicated patient without significant risk factors for extubation failure. In light of the evolving practice during the SARS CoV2 (COVID-19) pandemic to minimize aerosol generation and infection transmission, smooth extubation is particularly important.
\end{abstract}

\section{Introduction}

It has been recognized that tracheal extubation is associated with a significant risk of complications $[1,2]$. Both the severity and frequency of extubation-related adverse events [3-6] and the paucity of literature regarding extubation techniques highlight a need to incorporate strategies for extubation in airway management guidelines [5, 7]. The Difficult Airway Society (DAS) developed a guideline for the management of tracheal extubation in 2012 [7]. This guideline focused on creating an extubation strategy before the onset of anesthesia, classified patients into low and high risk for extubation failure, and discussed general techniques on implementation of extubation [7].

While the DAS guideline provides an excellent starting point in developing strategies for achieving a successful extubation, it does not provide a distinction between successful extubation and smooth extubation. The concept of smooth emergence was mentioned in the DAS guideline as desirable for the success of certain surgical procedures, but it did not specify which procedures [7]. In addition, like much of the discussion regarding extubation techniques in the literature, a precise definition of "smooth extubation" was not stated [7].
It should be noted that the COVID-19 pandemic has heightened the importance of developing our knowledge of effective techniques to achieve smooth emergence. In an effort to reduce the transmission of COVID-19 to healthcare workers, various barriers or altered extubation setups have been devised to physically shield workers from aerosol and droplets generated during extubation [8-11]. Their effectiveness remains unknown, however. A smooth extubation may enhance primary prevention by reducing coughing, bucking, and aerosolization [12].

This narrative review will review the definition of smooth extubation and propose a specific definition for this term in an effort to suggest a uniform nomenclature facilitating interpretation and comparisons in future studies on smooth extubation. It will then discuss categories of adverse events associated with extubation in adults, although some of the referenced literature is based on a pediatric population. Finally, we will review different smooth extubation techniques, pharmacologic aids, and adjunct maneuvers to achieve smooth extubation success in the setting of perioperative care of an uncomplicated patient without significant risk factors for extubation failure. Although related, techniques for the smooth extubation in the difficult airway are beyond the scope of this review. 


\section{Definition of Smooth Extubation}

As a result of limited practice guidelines and algorithms regarding extubation, there is a lack of a clear distinction on the difference between smooth and successful extubation. Successful extubation may indicate a purely respiratory level of success with patients tolerating the removal of the endotracheal tube, while a "smooth extubation" may include the lack of any physiologic responses that can lead to adverse outcomes from extubation. This distinction bears importance as many of the previous studies on criteria for successful extubation were conducted on critically ill patients on long-term ventilation [13]. The criteria for successful extubation in ICU patients may not apply to postoperative patients without significant risk for extubation failure.

Further, studies have mentioned "smooth extubation" and "smooth emergence" without a consensus of what these terms entail. We will use these terms interchangeably as they are often discussing the same desired outcome. The ambiguity on the factors of smooth emergence has led to the inclusion of different criteria in various papers. For example, a study by Lee et al. considered any coughing at all to be a failed smooth emergence [14]. Other studies expanded their definition of failed smooth extubation to include straining, movement, coughing, breath holding, or laryngospasm [15-17]. Hemodynamic perturbations, despite being potentially dangerous etiology of poor outcomes, were not considered as criteria in smooth emergence in either study.

We propose that smooth extubation should be a tranquil maneuver with minimal patient reaction and discomfort, stable vital signs, and maintenance of acceptable ventilation and oxygenation.

This definition may not be all-encompassing and further research is needed to elucidate usefulness of these criteria as a group in evaluating the success of smooth extubation and any additional factors that are necessary to ensure a smooth extubation.

\section{Adverse Events Associated with Extubation}

In the context of extubation, adverse events can be sorted into three major categories: respiratory, traumatic, and hemodynamic. Many of these adverse events can result in the depletion of oxygen stores at extubation, resulting in postoperative hypoxia. In severe cases, hypoxia can lead to hypoxic brain injury, cardiovascular injury, and possibly death [18]. Furthermore, it has been noted that a majority of emergency tracheal reintubations after perioperative extubation were due to preventable anesthesia-related factors [19]. These adverse events, summarized in Table 1, should be avoided with a smooth emergence.

3.1. Respiratory. Approximately $5 \%$ of patients undergoing inpatient noncardiac surgery experience a major pulmonary complication which is associated with significant risk of mortality $[20,21]$. Many of the respiratory effects of extubation are due to the alteration of laryngeal reflexes. Exaggerated laryngeal reflexes can result in coughing, bucking,
TABLE 1: Adverse events associated with extubation.

\begin{tabular}{|c|c|}
\hline Type of event & Examples \\
\hline Airway irritation & $\begin{array}{c}\text { Coughing } \\
\text { Bucking on endotracheal tube } \\
\text { Laryngospasm }\end{array}$ \\
\hline Hemodynamic perturbations & $\begin{array}{c}\text { Arrhythmia } \\
\text { Tachycardia/bradycardia } \\
\text { Hypo/hypertension } \\
\text { Myocardial ischemia }\end{array}$ \\
\hline $\begin{array}{l}\text { Airway/oropharyngeal } \\
\text { injuries }\end{array}$ & $\begin{array}{c}\text { Larynx including glottis } \\
\text { Laryngeal nerves } \\
\text { Oropharynx (tongue, uvula) } \\
\text { Dentition }\end{array}$ \\
\hline Compromised ventilation & $\begin{array}{c}\text { Respiratory depression } \\
\text { Airway obstruction } \\
\text { Airway edema } \\
\text { Aspiration } \\
\text { Pulmonary edema } \\
\text { Residual neuromuscular } \\
\text { blockade }\end{array}$ \\
\hline Patient distress & $\begin{array}{c}\text { Sore throat } \\
\text { Hoarse voice } \\
\text { Unexpected awareness } \\
\text { Posttraumatic stress disorder }\end{array}$ \\
\hline Surgical disruption & $\begin{array}{c}\text { Bleeding } \\
\text { Wound dehiscence } \\
\text { Flap disruption }\end{array}$ \\
\hline
\end{tabular}

or laryngospasm. Coughing and bucking may increase arterial pressure, heart rate, and intraocular and intracranial pressure. Bucking is defined as a more forceful and prolonged cough which can physiologically imitate a Valsalva maneuver but at variable lung volumes, potentially leading to hypoxemia. Protracted bucking can also rarely lead to abdominal wound separation [13]. Reduced airway muscle responses, resulting in decreased airway tone and obstruction, are also associated with adverse outcomes. Laryngeal functional disturbance can lead to an inability to sense foreign material for at least four hours, even in apparently alert patients [22], increasing the risk of aspiration and pneumonia. Pulmonary aspiration of gastric contents was the third most common respiratory event leading to anesthesia malpractice claims from 1990-2007 [5]. In the Fourth National Audit Project of the Royal College of Anesthetists (NAP4), aspiration was found to be the most common primary cause of death in anesthesia-related events [3]. The most common reason for reduced airway patency and decreased reactivity postoperatively is thought to be the relaxation of pharyngolaryngeal muscles due to residual effects of inhalational anesthetics and/or the inadequate reversal of neuromuscular blockade, leading to significant risk of postoperative pulmonary complications [21, 23]. While neostigmine and glycopyrrolate have traditionally been used to reverse neuromuscular blockade in the United States, Sugammadex was introduced for reversal of neuromuscular blockade in 2015. [21] Recent studies have shown a 30\% reduced risk of pulmonary complications, $47 \%$ reduced risk of pneumonia, a $55 \%$ reduced risk of respiratory failure, and reduction in odds of reintubation for respiratory failure or 
new noninvasive ventilation with the use of Sugammadex compared to neostigmine $[21,24]$. This favors the use of Sugammadex for most extubations.

3.1.1. Laryngospasm. In the context of extubation, laryngospasm is the most common cause of upper airway obstruction, occurring most often after removal of the endotracheal tube. Laryngospasm has previously been narrowly defined as an occlusion of the glottis by the reflexive action of the intrinsic laryngeal muscles. In addition to the glottis, closure of the larynx due to laryngospasm can also occur at all levels of the upper airway, including the aryepiglottic folds and the false vocal cords [25]. Laryngospasm is precipitated by local irritation of the vocal cords by stimuli such as secretions, blood, inflow of cold, dry air from oxygen flush from anesthesia circuit, or a foreign body including an endotracheal tube $[13,25]$. It serves as a protective reflex to prevent foreign material from entering the tracheobronchial tree but can be detrimental in the perioperative setting as the closure of the airway in laryngospasm can continue beyond the cessation of the provoking stimulus. This can lead to complete airway obstruction with hypoxia and hypercarbia, and when untreated, can result in negative pressure pulmonary edema, and even hypoxic cardiac arrest [7].

3.1.2. Negative Pressure Pulmonary Edema. Negative pressure pulmonary edema, also known as postobstructive pulmonary edema, is most commonly caused by laryngospasm but can occur as a result of any cause of complete airway obstruction, which can happen at the time of extubation. The pathogenesis is multifactorial, but the dominant mechanism is likely due to forceful inspiratory efforts against an obstructed airway causing negative intrathoracic pressure leading to pulmonary edema [2]. The treatment often requires endotracheal reintubation, mechanical ventilation, and diuresis [26].

3.2. Trauma. Difficult extubation can result in trauma to the upper and lower airways, most commonly resulting in damage to the larynx and the vocal cords. According to the ASA Closed Claims Database, $80 \%$ of the laryngeal nerve injuries followed routine airway management [4]. Although occurring at intubation, the injuries manifest at or after extubation. Excessive suctioning during extubation has also been noted to cause trauma to the mobile structures in the upper airway, such as the arytenoid cartilages [2]. Injury to the vagus nerve or the recurrent laryngeal nerve can cause vocal cord paralysis. Bilateral vocal cord paralysis can cause airway obstruction that can require emergent reintubation; this may rarely occur after head and neck surgery [2]. Local oropharyngeal trauma with extubation can result in edema, causing airway compromise requiring reintubation [2]. Anesthesia-related dental trauma has been noted to occur more commonly during intubation [27], but 9-20\% of these injuries occur during extubation or in the recovery room [28]. Laryngeal injuries range in severity from minor, soft tissue edema, erythema, hematoma, ulceration, mass lesions, stenosis, and immobility of the vocal cords [29]. Lingual trauma, such as laceration due to a patient biting their tongue during emergence, or lingual hematoma, has also been documented, but the incidence during extubation is unknown. Various bite blocks are in use to prevent lingual trauma; nevertheless, severe pressure injury to the tongue has been reported which becomes apparent upon extubation [30]. Emotional distress can also result from awareness during extubation, potentially leading to deleterious sequelae such as symptoms of posttraumatic stress disorder and a permanent phobia to surgery and anesthesia [31-33]. Finally, as mentioned above, protracted bucking can lead to surgical incision breakdown as well as impaired ventilation leading to hypoxia [13].

3.3. Hemodynamic Shifts. The act of extubation itself is physiologically stressful and has been shown to cause increases in blood pressure and heart rate [13, 15, 34-36]. In addition, coughing can lead to increases in intrathoracic pressure which can interfere with venous return to the heart [37]. Drugs commonly used in preparation for extubation, such as glycopyrrolate, can cause tachycardia which leads to an increase in myocardial demand and can result in myocardial ischemia [38]. While transient hemodynamic shifts as a result of extubation are usually well tolerated in patients without coexisting disease, some patients demonstrate an exaggerated response [13]. Patients who have undergone neurosurgical operations are particularly sensitive to postoperative disturbances of autoregulation of cerebral blood flow, with hypertension resulting in brain hemorrhage and/ or herniation [2].

\section{Smooth Emergence Techniques}

4.1. Deep Extubation. Although awake and deep extubation may have similar risks when incorrectly performed, anesthesiologists often associate deep extubation with an increased risk of aspiration, laryngospasm, and loss of airway control compared to awake extubation [39]. Despite its perceived risks, deep extubation can also help avoid many of the potential airway irritant and hemodynamic complications, such as coughing/bucking, tachycardia, and hemodynamic swings [39].

Several studies reported decreased incidence of persistent cough with deep extubation with no change in overall incidence of perioperative adverse events between deep extubation and awake extubation [40-42]. A recent systematic review and meta-analysis of deep extubation in a pediatric population found that while deep extubation reduces the risk of overall airway complications, there is an increased risk of airway obstruction. Further, there was no difference in the incidence of laryngospasm between the deep and awake extubation group [43].

Given the lack of data, anesthesiologists often rely on clinical experience when deciding to perform a deep extubation. In a study surveying extubation practice in adult surgical patients, the most common reasons cited for not 
performing deep extubation were lack of necessity and concern regarding potential laryngospasm and aspiration [37]. Based upon the available evidence, these concerns might not be fully supported and should be reassessed.

Furthermore, deep extubation can be combined with different techniques to increase the success rate of smooth emergence. A study comparing deep extubation with desflurane and remifentanil with a control of only desflurane showed a reduction in recovery time and incidence of respiratory complications in the combined desflurane/remifentanil group [44]. Another study investigated smooth emergence of adult patients with otologic surgery after deep extubation with inhaled anesthetic agent combined with either remifentanil $(0.03 \mathrm{mcg} / \mathrm{kg}$ over 10 -minute infusion), dexmedetomidine $(0.5 \mathrm{mcg} / \mathrm{kg}$ over 10 -minute infusion), or dexmedetomidine $(0.7 \mathrm{mcg} / \mathrm{kg}$ over 10 -minute infusion). While the outcomes were not compared to a control group of awake extubation, only one patient in the study developed desaturation and laryngospasm, and no patient required reintubation. All groups had low incidence of cough during extubation. The dexmedetomidine $0.7 \mathrm{mcg} / \mathrm{kg}$ and the remifentanil groups provided similar rates of smooth emergence compared to the dexmedetomidine $0.5 \mathrm{mcg} / \mathrm{kg}$ group. In addition, both dexmedetomidine groups had the added advantage of opioid sparing effects and less postoperative nausea and vomiting than remifentanil [45]. It is reasonable to infer from this study that dexmedetomidine may be an underutilized tool in clinical practice to achieve smooth extubation. The reasons for underutilization may include concerns regarding added cost [46] or delayed emergence [47].

4.2. ETT Exchange to Laryngeal Mask Airway (LMA). LMAs have been shown to be a possibly useful adjunct in achieving smooth emergence [48]. In a study of 60 patients, patients were treated with either traditional awake removal of ETT or exchange of ETT with LMA followed by awake extubation with LMA. The incidence of both respiratory complications and significant hemodynamic shifts was decreased in the group with LMA exchange [49]. A similar study achieved the same results in elderly patients with hypertension [50].

4.3. "No-Touch" Extubation. A "no-touch" extubation is a technique in which absolutely no stimulation is allowed until patients spontaneously wake up. Tsui et al. reported successful "no-touch" extubation of twenty patients in whom there were no instances of laryngospasm or coughing [51]. Similarly, Sheta et al. noted a decrease in the incidence of laryngospasm in the "no-touch" group compared to the control group, awakened with stimuli. Furthermore, the "no-touch" extubation had significantly less severe cough, excess secretions, breath holding, hoarseness, biting, occurrence of nonpurposeful movements, and changes in heart rate, systolic blood pressure, and diastolic blood pressure. However, there was no significant difference in the incidence of postoperative sore throat [52].

\section{Pharmacologic Aids of Tracheal Extubation}

A variety of pharmacological treatments have been studied to improve emergence. The efficacy of these medications is often difficult to compare due to the use of different definitions of smooth extubation and studies measuring different effects. Many of these studies are often also subject to small sample sizes and are usually tested on ASA I-II patients undergoing elective surgeries. It should be noted that these pharmacologic aids may not have the same efficacy in highrisk patients. Despite these limiting factors, we discuss some of the more widely studied medications below (Table 2) $[13,15,34-36,45,47,53-56,59-63]$. Other pharmacologic agents, such as ketamine, have been used to achieve smooth emergence [64]. However, there is less published literature on its efficacy in the setting of smooth extubation with adults and it will not be discussed.

5.1. Intracuff Lidocaine. The cuff of the endotracheal tube (ETT) has been suggested as a potential reservoir for local anesthetics, such as lidocaine, to decrease the incidence of postoperative sore throat and cough. There have been some concerns that lidocaine would not be able to diffuse through the ETT cuff. However, in vitro and in vivo studies have shown that lidocaine is able to diffuse through the ETT cuff, albeit rather slowly $[65,66]$. Alkalinization or a combination of warming and alkalinization of the anesthetic can increase the proportion of the uncharged drug available for diffusion, thereby increasing the rate of diffusion [67]. Many studies have demonstrated the efficacy of intracuff lidocaine in decreasing cough and sore throat [53-55]. Two systematic reviews and meta-analyses demonstrated that both alkalinized and nonalkalinized intracuff lidocaine showed significant reduction of postoperative sore throat, coughing, and dysphonia compared to control groups without intracuff lidocaine $[53,54]$.

5.2. Intravenous (IV) Lidocaine. IV lidocaine has long been studied as an agent to suppress laryngospasm and the cardiovascular response to extubation $[13,34,35]$. However, it should be noted that evidence from other studies has not always supported the efficacy of lidocaine to attenuate or prevent these changes [2]. A systematic review and metaanalysis of the use of IV lidocaine to achieve smooth extubation showed that treatment led to large reductions in postextubation cough and sore throat. However, there was no difference in the incidence of laryngospasm or adverse events compared to the control [56].

5.3. Topical Lidocaine, Methylprednisolone, and Benzydamine Hydrochloride. In addition to intracuff and IV delivery of lidocaine, lidocaine can also be administered topically in the oropharynx and glottis. Zamora Lozano et al. demonstrated that topical administration is not as effective as intracuff or IV administration in reducing the incidence of cough during emergence [55]. In addition, application of lidocaine spray to the oropharyngeal cavity before intubation seems to 
TABLE 2: Comparison of pharmacologic adjuncts used in smooth emergence.

\begin{tabular}{|c|c|c|c|c|c|c|c|}
\hline Techniques & $\begin{array}{l}\text { Intracuff } \\
\text { lidocaine }\end{array}$ & IV lidocaine & $\begin{array}{c}\text { IV } \\
\text { dexmedetomidine }\end{array}$ & $\begin{array}{l}\text { IV } \\
\text { remifentanil }\end{array}$ & $\begin{array}{l}\text { IV calcium } \\
\text { channel } \\
\text { blockers }\end{array}$ & $\begin{array}{c}\text { Topical } \\
\text { benzydamine } \\
\text { hydrochloride }\end{array}$ & $\begin{array}{c}\text { Topical } \\
\text { methylprednisolone }\end{array}$ \\
\hline $\begin{array}{l}\text { Proposed } \\
\text { advantages }\end{array}$ & $\begin{array}{c}\text { Reduction of } \\
\text { postoperative } \\
\text { cough, sore } \\
\text { throat } \\
{[53,54] \text {, and }} \\
\text { dysphonia } \\
\text { [55]. }\end{array}$ & $\begin{array}{c}\text { Attenuate } \\
\text { increases in } \\
\text { heart rate and } \\
\text { mean arterial } \\
\text { pressure } \\
{[13,34,35]} \\
\text { and } \\
\text { postoperative } \\
\text { cough and } \\
\text { sore throat } \\
{[56] .}\end{array}$ & $\begin{array}{c}\text { Reduction of } \\
\text { postoperative } \\
\text { cough }[15,44], \\
\text { nausea, and } \\
\text { vomiting [45]. } \\
\text { Increased } \\
\text { respiratory rate } \\
\text { [45]. Decreased } \\
\text { agitation and need } \\
\text { for rescue } \\
\text { analgesic }[45,47] .\end{array}$ & $\begin{array}{c}\text { Attenuate } \\
\text { increases in } \\
\text { heart rate and } \\
\text { mean arterial } \\
\text { pressure [36]. } \\
\text { Reduction of } \\
\text { postoperative } \\
\text { cough } \\
{[36,44] .}\end{array}$ & $\begin{array}{c}\text { Attenuate } \\
\text { increases in } \\
\text { heart rate and } \\
\text { mean arterial } \\
\text { pressure } \\
{[57,58] .}\end{array}$ & $\begin{array}{c}\text { Decreased } \\
\text { postoperative } \\
\text { sore throat } \\
{[59,60] .}\end{array}$ & $\begin{array}{c}\text { Decreased } \\
\text { postoperative sore } \\
\text { throat and cough } \\
{[61] .}\end{array}$ \\
\hline $\begin{array}{l}\text { Proposed } \\
\text { disadvantages }\end{array}$ & $\begin{array}{l}\text { Unknown } \\
\text { systemic } \\
\text { absorption. }\end{array}$ & $\begin{array}{l}\text { Cardiac } \\
\text { arrhythmia } \\
\text { local } \\
\text { anesthetic } \\
\text { toxicity } \\
\text { (LAST). }\end{array}$ & $\begin{array}{c}\text { Increased } \\
\text { sedation, } \\
\text { bradycardia, } \\
\text { hypotension [15], } \\
\text { time to emergence } \\
\text { [47]. Expensive. }\end{array}$ & $\begin{array}{l}\text { Increased } \\
\text { postoperative } \\
\text { nausea and } \\
\text { vomiting. } \\
\text { Added } \\
\text { expense. }\end{array}$ & $\begin{array}{l}\text { Hypotension. } \\
\text { Heart block. } \\
\text { Bradycardia. }\end{array}$ & $\begin{array}{c}\text { Burning } \\
\text { sensation and } \\
\text { possible } \\
\text { vomiting } \\
\text { when applied } \\
{[60] .}\end{array}$ & $\begin{array}{l}\text { Limited evidence. } \\
\text { Systemic steroid } \\
\text { absorption. Steroid } \\
\text { effects. }\end{array}$ \\
\hline
\end{tabular}

increase the incidence of postoperative sore throat in a dosedependent manner [59]. Furthermore, Watkins et al. found that topical lidocaine increased the mean times for extubation by nearly 2 minutes [62]. In comparison, topical methylprednisolone [61] and ETT cuff coated benzydamine hydrochloride $[59,60]$ have both been shown to improve postoperative sore throat compared to topical lidocaine but are not as widely used in clinical practice.

5.4. IV Dexmedetomidine. Dexmedetomidine can be used as a sedative agent without the added risk of respiratory depression [63] and can aid in smooth emergence. Bindu et al. demonstrated that IV infusion of 0.75 microgram per kilogram $(\mathrm{mcg} / \mathrm{kg})$ of dexmedetomidine fifteen minutes before the end of surgery reduced the amount of coughing upon emergence [15]. Patients treated with dexmedetomidine were slightly more sedated upon emergence and had increased incidence of bradycardia and hypotension, but no significant sequelae as a result [15]. Fan et al. found that a 10minute IV infusion of $0.5 \mathrm{mcg} / \mathrm{kg}$ or $0.7 \mathrm{mcg} / \mathrm{kg}$ of $\mathrm{dex}-$ medetomidine for deep extubation resulted in an increased rate of smooth emergence, increased respiratory rate, decreased need for rescue analgesic, and less postoperative nausea and vomiting compared to extubation with 10minute infusion of $0.04 \mathrm{mcg} / \mathrm{kg}$ of IV remifentanil [45]. A study by Guler et al. found that there were decreased agitation and pain scores and decreased amount of severe coughing with treatment with $0.5 \mathrm{mg} / \mathrm{kg}$ IV dexmedetomidine 5 minutes before the end of surgery compared to placebo. However, times to emergence were significantly longer in the treatment group [47]. A systematic review and meta-analysis of $0.4 \mathrm{mcg}-0.5 \mathrm{mcg} / \mathrm{kg}$ of dexmedetomidine supports its use to achieve smooth extubation without causing respiratory depression. However, higher doses resulted in bradycardia, hypotension, and sedation [68].
Dexmedetomidine will be discussed further below in combination with deep extubation.

5.5. IV Remifentanil. Remifentanil is an ultrashort acting opioid which can be used to achieve smooth emergence. A study by Nho et al. found that IV infusion of remifentanil via target controlled infusion system to target concentration of 1 nanogram per milliliter at the end of surgery attenuated increases in heart rate and incidence of moderate or severe coughing during emergence compared to the control group. The mean arterial pressure was also lower in the treatment group during recovery [36]. However, as discussed previously, remifentanil was not as effective as dexmedetomidine at facilitating smooth emergence [45]. It should be noted that other opioids, such as fentanyl and tramadol, may be used as an aid in smooth extubation $[16,69]$.

5.6. IV Calcium Channel Blockers. Calcium channel blockers, such as verapamil and diltiazem, can be used to attenuate the hemodynamic responses to emergence. A study by Mikawa et al. found that IV administration of verapamil $0.05 \mathrm{mg} / \mathrm{kg}$, verapamil $0.1 \mathrm{mg} / \mathrm{kg}$, or diltiazem $0.2 \mathrm{mg} / \mathrm{kg}$ two minutes before extubation could attenuate increases in heart rate as well as systolic and diastolic pressure compared to a control group of IV saline. $0.1 \mathrm{mg} / \mathrm{kg}$ of verapamil had the greatest effect on the attenuation of the hemodynamic changes. None of the patients developed hypotension, bradycardia, or sinoatrial or atrioventricular block severe enough to warrant intervention [58]. Another study by Swamy and Madhusudhana found that a combined dose of IV administration diltiazem $0.2 \mathrm{mg} / \mathrm{kg}$ or $0.1 \mathrm{mg} / \mathrm{kg}$ and lidocaine $1.0 \mathrm{mg} / \mathrm{kg}$ was more effective at attenuating hemodynamic changes than just $1.0 \mathrm{mg} / \mathrm{kg}$ lidocaine alone [57]. 
TABLE 3: Adjunct maneuvers to maintaining successful extubation.

\begin{tabular}{|c|c|}
\hline Maneuver & Description \\
\hline Preoxygenation with $100 \%$ FiO2 $[13,18,48,70-72]$ & Maximizing FRC content of oxygen \\
\hline Bite block placement before extubation [7, 73-77] & $\begin{array}{c}\text { Minimizing endotracheal tube obstruction and oral, lingual, and dental } \\
\text { injury }\end{array}$ \\
\hline $\begin{array}{l}\text { Patient monitoring during transfer to recovery } \\
{[18,75,78-83]}\end{array}$ & Capnography and/or pulse oximetry during transfer \\
\hline Supplemental oxygen during transfer to recovery $[18,80,81]$ & Preventing hypoxemia during transfer \\
\hline
\end{tabular}

\section{Adjunct Maneuvers to Smooth Extubation}

In addition to pharmaceutical adjuncts, there are also several adjunct maneuvers that have been studied to improve emergence (Table 3).

6.1. Preoxygenation with 100\% Fraction of Inspired Oxygen (FiO2) prior to Extubation. Preoxygenation with $100 \% \mathrm{FiO} 2$ should be considered at emergence to maximize pulmonary oxygen stores. This allows for functional reserve capacity of oxygen available in case of airway obstruction or unanticipated hypoxia $[13,18,48]$. There have been some concerns that preoxygenation with $100 \% \mathrm{FiO} 2$ prior to extubation can lead to worsened atelectasis in the postoperative setting $[70,71]$. However, there is a lack of sufficient evidence that preextubation oxygenation causes postoperative hypoxia due to atelectasis or other clinically significant untoward effects on patients [72].

6.2. Bite Blocks. Upon emergence, patients may become agitated or delirious and bite down on the endotracheal tube. This has resulted in partial occlusion [84-88] or complete transection of the endotracheal tube [89], causing airway obstruction $[84,85,88]$, and negative pressure pulmonary edema [90]. Thus, bite blocks should be used during emergence to prevent such an occurrence [7]. There is insufficient evidence to demonstrate whether soft bite blocks, such as rolled or taped gauze, or hard bite blocks are better at maintaining airway patency during extubation. There has been some support for use of soft bite blocks as opposed to hard bite blocks in preventing oral injuries, as hard bite blocks may cause pressure injuries and dental trauma [91]. An oropharyngeal airway has been suggested as a hard bite block which simultaneously provides a patent upper airway [7]. However, the oropharyngeal airway does not always prevent a patient from biting down and occluding an endotracheal tube [73] and its use can potentially lead to dental trauma [74], aspiration of the oropharyngeal airway [75], and dislodgement into the esophagus [76].

6.3. Patient Monitoring and Supplemental Oxygen Use during Transfer to Recovery Room. Hypoxemia can lead to severe adverse outcomes. Postoperative hypoxemia occurs commonly [74] and has been documented even after minor procedures [77] and may remain unrecognized unless the patient is monitored with a pulse oximeter [78]. Ventilatory depression likewise may go unrecognized, unless capnography is utilized [3]. Patients are particularly vulnerable to hypoxemia during transfer from the operating room to the recovery room as ventilation is likely to be depressed from residual anesthetics and other sedatives used in general anesthesia [79, 80]. Despite the frequency and risk of postoperative hypoxemia, pulse oximeters and capnography are not always routinely used in practice to monitor patients during transfer from the operating room to the recovery room $[81,82]$.

The risk of postoperative hypoxemia is increased if the patient is breathing room air during transfer to the recovery room despite preoxygenation and an acceptable minute ventilation, if there is an excessive A-a DO2 [79]. A study by Maity et al. demonstrated that none of the patients recently extubated who received supplemental oxygen during transport developed hypoxemia, while hypoxemia was identified in approximately $30 \%$ of patients who were breathing room air during transport [83]. Furthermore, a study by Tyler et al. showed that all patients who developed hypoxemia during transfer with room air returned to normoxia when supplemental oxygen was supplied. The study concluded that supplemental oxygen during transfer may have prevented the incidence of hypoxemia [79]. It is recommended that oxygen supplementation should be given to all patients who have undergone general anesthesia during the transfer from the operating room to the recovery room $[18,80]$, as well as monitoring by pulse oximeter to detect and treat hypoxemia as soon as possible $[1,83]$.

\section{Conclusion}

Smooth extubation and successful extubation are often mistakenly considered to be equivalent events. In clinical practice, the goals and advantages of smooth extubation exceed the minimum requirement of maintenance of respiratory function. In this review, we have proposed five factors that should be included in the definition and practice of smooth extubation. They include limited respiratory tract irritation, avoidance of significant hemodynamic shifts, avoidance of iatrogenic injury, maintaining airway patency and physiologic oxygenation/ventilation, and patient comfort.

These factors have previously been described separately and independently, primarily in the context of safety of extubation in general, and anesthesia-related closed claims registries $[4,5]$. However, we propose a unifying concept: to include all these factors as a singular definition in order to provide clarity on the concept of smooth extubation. Further 
research is necessary to establish the utility of using this definition in clinical practice. We believe, however, that adding standardization to the conceptual framework and language of the technique of smooth extubation will help facilitate further research and provide guidance in clinical practice while improving the techniques of extubation and promulgating education in their application.

In our literature review, we have identified three techniques to facilitate smooth extubation: exchanging the endotracheal tube for an LMA prior to extubation, limiting unnecessary stimulation on emergence, such as in the "notouch technique" described, and deep extubation. Deep extubation in particular may be underutilized in clinical practice due to unconfirmed concerns regarding laryngospasm and aspiration. Additional techniques to mitigate perioperative and postoperative patient harm include use of a bite block, preoxygenation prior to extubation, and use of supplemental oxygen and patient monitoring with pulse oximetry and/or capnography during patient transfer to the recovery room.

In addition, various pharmacologic interventions can be implemented to facilitate the utilization of these techniques. There is clinical evidence to support the use of IV and intracuff lidocaine to attenuate hemodynamic shifts, sore throat, and excessive bucking and coughing during extubation. The use of IV remifentanil and dexmedetomidine has also shown promise to facilitate smooth extubation. Dexmedetomidine may be more effective than remifentanil at preventing postoperative nausea and vomiting. However, it should be noted that dexmedetomidine may result in a slower emergence.

Further research is needed to elucidate the exact clinical circumstances in which these techniques may and should be safely utilized. It is our hope that additional investigations into the application of these pharmacologic and nonpharmacologic techniques with an understanding of the smooth extubation paradigm will improve patient outcomes and reduce the morbidity associated with perioperative extubation.

\section{Conflicts of Interest}

The authors declare that there are no conflicts of interest regarding the publication of this paper.

\section{References}

[1] K. Koga, T. Asai, R. S. Vaughan, and I. P. Latto, "Respiratory complications associated with tracheal extubation. Timing of tracheal extubation and use of the laryngeal mask during emergence from anaesthesia," Anaesthesia, vol. 53, no. 6, pp. 540-544, 1998.

[2] M. Hartley and R. S. Vaughan, "Problems associated with tracheal extubation," British Journal of Anaesthesia, vol. 71, no. 4, pp. 561-568, 1993.

[3] T. M. Cook, N. Woodall, and C. Frerk, "Major complications of airway management in the UK: results of the fourth national audit project of the royal college of anaesthetists and the difficult airway society. Part 1: anaesthesia $\dagger, "$ British Journal of Anaesthesia, vol. 106, no. 5, pp. 617-631, 2011.
[4] K. B. Domino, K. L. Posner, R. A. Caplan, and F. W. Cheney, "Airway injury during anesthesia: a closed claims analysis," Anesthesiology, vol. 91, no. 6, pp. 1703-1711, 1999.

[5] J. Metzner, K. L. Posner, M. S. Lam, and K. B. Domino, "Closed claims' analysis," Best Practice \& Research Clinical Anaesthesiology, vol. 25, no. 2, pp. 263-276, 2011.

[6] G. N. Peterson, K. B. Domino, R. A. Caplan, K. L. Posner, L. A. Lee, and F. W. Cheney, "Management of the difficult airway: a closed claims analysis," Anesthesiology, vol. 103, no. 1, pp. 33-39, 2005.

[7] M. Popat, V. Mitchell, R. Dravid, A. Patel, C. Swampillai, and A. Higgs, "Difficult airway society guidelines for the management of tracheal extubation," Anaesthesia, vol. 67, no. 3, pp. 318-340, 2012.

[8] C. T. Matava, J. Yu, and S. Denning, "Clear plastic drapes may be effective at limiting aerosolization and droplet spray during extubation: implications for COVID-19," Canadian Journal of Anesthesia/Journal Canadien D’anesthésie, vol. 67, no. 7, pp. 902-904, 2020.

[9] S. Brown, F. Patrao, S. Verma, A. Lean, S. Flack, and D. Polaner, "Barrier system for airway management of COVID-19 patients," Anesthesia \& Analgesia, vol. 131, 2020.

[10] P. S. Au Yong and X. Chen, "Reducing droplet spread during airway manipulation: lessons from the COVID-19 pandemic in Singapore," British Journal of Anaesthesia, vol. 125, no. 1, pp. e176-e178, 2020.

[11] D. F. D'Silva, T. J. McCulloch, J. S. Lim, S. S. Smith, and D. Carayannis, "Extubation of patients with COVID-19," British Journal of Anaesthesia, vol. 125, no. 1, pp. e192-e195, 2020.

[12] R. Aminnejad, A. Salimi, and M. Saeidi, "Lidocaine during intubation and extubation in patients with coronavirus disease (COVID-19)," Canadian Journal of Anesthesia/Journal Canadien D’anesthésie, vol. 67, no. 6, p. 759, 2020.

[13] K. A. Miller, C. P. Harkin, and P. L. Bailey, "Postoperative tracheal extubation," Anesthesia \& Analgesia, vol. 80, no. 1, pp. 149-172, 1995.

[14] B. Lee, J.-R. Lee, and S. Na, “Targeting smooth emergence: the effect site concentration of remifentanil for preventing cough during emergence during propofol-remifentanil anaesthesia for thyroid surgery," British Journal of Anaesthesia, vol. 102, no. 6, pp. 775-778, 2009.

[15] B. Bindu, S. Pasupuleti, U. P. Gowd, V. Gorre, R. R. Murthy, and M. B. Laxmi, "A double blind, randomized, controlled trial to study the effect of dexmedetomidine on hemodynamic and recovery responses during tracheal extubation," Journal of Anaesthesiology, Clinical Pharmacology, vol. 29, no. 2, pp. 162-167, 2013.

[16] P. Rani, V. Hemanth Kumar, M. Ravishankar, T. Sivashanmugam, R. Sripriya, and M. Trilogasundary, "Rapid and reliable smooth extubation - comparison of fentanyl with dexmedetomidine: a randomized, double-blind clinical trial," Anesthesia: Essays and Researches, vol. 10, no. 3, pp. 597-601, 2016.

[17] K. A. Cranfield and L. M. Bromley, "Minimum alveolar concentration of desflurane for tracheal extubation in deeply anaesthetized, unpremedicated children," British Journal of Anaesthesia, vol. 78, no. 4, pp. 370-371, 1997.

[18] L. Foulds and A. Dalton, "Extubation and emergence," Anaesthesia \& Intensive Care Medicine, vol. 19, no. 9, pp. 465470, 2018.

[19] J. P. Mathew, S. H. Rosenbaum, T. O'Connor, and P. G. Barash, "Emergency tracheal intubation in the 
postanesthesia care unit: physician error or patient disease?" Anesthesia \& Analgesia, vol. 71, no. 6, pp. 691-697, 1990.

[20] R. E. Freundlich, M. D. Maile, J. J. Sferra, E. S. Jewell, S. Kheterpal, and M. Engoren, "Complications associated with mortality in the national surgical quality improvement program Database," Anesthesia \& Analgesia, vol. 127, no. 1, pp. 55-62, 2018.

[21] S. Kheterpal, M. T. Vaughn, T. Z. Dubovoy et al., "Sugammadex versus neostigmine for reversal of neuromuscular blockade and postoperative pulmonary complications (stronger): a multicenter matched cohort analysis," Anesthesiology, vol. 132, no. 6, pp. 1371-1381, 2020.

[22] G. E. Burgess, J. R. Cooper Jr., R. J. Marino, M. J. Peuler, and R. A. Warriner, "Laryngeal competence after tracheal extubation," Anesthesiology, vol. 51, no. 1, pp. 73-77, 1979.

[23] E. Kirmeier, "Post-anaesthesia pulmonary complications after use of muscle relaxants (POPULAR): a multicentre, prospective observational study," Lancet Respiratory Medicine, vol. 7, no. 2, pp. 129-140, 2019.

[24] M. Krause, S. K. McWilliams, K. J. Bullard et al., "Neostigmine versus Sugammadex for reversal of neuromuscular blockade and effects on reintubation for respiratory failure or newly initiated noninvasive ventilation: an interrupted time series design," Anesthesia and Analgesia, vol. 131, no. 1, pp. 141-151, 2020.

[25] K. S. Sibert, J. L. Long, and S. M. Haddy, "Extubation and the risks of coughing and laryngospasm in the era of coronavirus disease-19 (COVID-19)," Cureus, vol. 12, no. 5, Article ID e8196, 2020.

[26] M. Bhattacharya, R. H. Kallet, L. B. Ware, and M. A. Matthay, "Negative-pressure pulmonary edema," Chest, vol. 150, no. 4, pp. 927-933, 2016.

[27] M. E. Warner, S. M. Benenfeld, M. A. Warner, D. R. Schroeder, and P. M. Maxson, "Perianesthetic dental injuries," Anesthesiology, vol. 90, no. 5, pp. 1302-1305, 1999.

[28] J. S. Yasny, "Perioperative dental considerations for the anesthesiologist," Anesthesia \& Analgesia, vol. 108, no. 5, pp. 1564-1573, 2009.

[29] M. B. Brodsky, M. J. Levy, E. Jedlanek et al., "Laryngeal injury and upper airway symptoms after oral endotracheal intubation with mechanical ventilation during critical care," Critical Care Medicine, vol. 46, no. 12, pp. 2010-2017, 2018.

[30] J. F. Ha, L. N. Vitale, M. A. Pfarr, Y. Kawai, and D. A. Zopf, "Massive macroglossia after posterior cranial fossa surgery: a case report," A \& A Practice, vol. 10, no. 8, pp. 204-208, 2018.

[31] S. R. Tasbihgou, M. F. Vogels, and A. R. Absalom, "Accidental awareness during general anaesthesia-a narrative review," Anaesthesia, vol. 73, no. 1, pp. 112-122, 2018.

[32] J. E. Osterman and B. A. van der Kolk, "Awareness during anesthesia and posttraumatic stress disorder," General Hospital Psychiatry, vol. 20, no. 5, pp. 274-281, 1998.

[33] T. M. Cook, J. Andrade, D. G. Bogod et al., "The 5th National Audit Project (NAP5) on accidental awareness during general anaesthesia: patient experiences, human factors, sedation, consent and medicolegal issues," Anaesthesia, vol. 69, no. 10, pp. 1102-1116, 2014

[34] A. V. Bidwai, V. A. Bidwai, C. R. Rogers, and T. H. Stanley, "Blood-pressure and pulse-rate responses to endotracheal extubation with and without prior injection of lidocaine," Anesthesiology, vol. 51, no. 2, pp. 171-173, 1979.

[35] S. Hu, Y. Li, S. Wang, S. Xu, X. Ju, and L. Ma, "Effects of intravenous infusion of lidocaine and dexmedetomidine on inhibiting cough during the tracheal extubation period after thyroid surgery," BMC Anesthesiology, vol. 19, no. 1, p. 66, 2019.

[36] J.-S. Nho, S.-Y. Lee, J.-M. Kang et al., "Effects of maintaining a remifentanil infusion on the recovery profiles during emergence from anaesthesia and tracheal extubation," British Journal of Anaesthesia, vol. 103, no. 6, pp. 817-821, 2009.

[37] S. Rassam, M. Sandbythomas, R. S. Vaughan, and J. E. Hall, "Airway management before, during and after extubation: a survey of practice in the United Kingdom and Ireland," Anaesthesia, vol. 60, no. 10, pp. 995-1001, 2005.

[38] S. M. Mostafa and M. Vucevic, "Comparison of atropine and glycopyrronium in patients with pre-existing cardiac disease," Anaesthesia, vol. 39, no. 12, pp. 1207-1213, 1984.

[39] M. D. Daley, P. H. Norman, and L. A. Coveler, "Tracheal extubation of adult surgical patients while deeply anesthetized: a survey of United States anesthesiologists," Journal of Clinical Anesthesia, vol. 11, no. 6, pp. 445-452, 1999.

[40] R. G. Baijal, S. A. Bidani, C. G. Minard, and M. F. Watcha, "Perioperative respiratory complications following awake and deep extubation in children undergoing adenotonsillectomy," Paediatric Anaesthesia, vol. 25, no. 4, pp. 392-399, 2015.

[41] B. S. von Ungern-Sternberg, K. Davies, M. Hegarty, T. O. Erb, and W. Habre, "The effect of deep vs. awake extubation on respiratory complications in high-risk children undergoing adenotonsillectomy: a randomised controlled trial," European Journal of Anaesthesiology, vol. 30, no. 9, pp. 529-536, 2013.

[42] R. I. Patel, R. S. Hannallah, J. Norden, W. F. Casey, and S. T. Verghese, "Emergence airway complications in children: a comparison of tracheal extubation in awake and deeply anesthetized patients," Anesthesia and Analgesia, vol. 73, no. 3, pp. 266-270, 1991.

[43] C.-H. Koo, S. Lee, S. Chung, and J.-H. Ryu, "Deep vs. Awake extubation and LMA removal in terms of airway complications in pediatric patients undergoing anesthesia: a systemic review and meta-analysis," Journal of Clinical Medicine, vol. 7, no. 10, p. 353, 2018.

[44] M. K. Kim, C. W. Baek, H. Kang et al., "Comparison of emergence after deep extubation using desflurane or desflurane with remifentanil in patients undergoing general anesthesia: a randomized trial," Journal of Clinical Anesthesia, vol. 28, pp. 19-25, 2016.

[45] Q. Fan, C. Hu, M. Ye, and X. Shen, "Dexmedetomidine for tracheal extubation in deeply anesthetized adult patients after otologic surgery: a comparison with remifentanil," $B M C$ Anesthesiology, vol. 15, no. 1, p. 106, 2015.

[46] A. E. Patanwala and B. L. Erstad, "Comparison of dexmedetomidine versus propofol on hospital costs and length of stay," Journal of Intensive Care Medicine, vol. 31, no. 7, pp. 466-470, 2016.

[47] G. Guler, A. Akin, Z. Tosun, S. Ors, A. Esmaoglu, and A. Boyaci, "Single-dose dexmedetomidine reduces agitation and provides smooth extubation after pediatric adenotonsillectomy," Paediatric Anaesthesia, vol. 15, no. 9, pp. 762-766, 2005.

[48] C. A. Artime and C. A. Hagberg, "Tracheal extubation," Respiratory Care, vol. 59, no. 6, pp. 991-1005, 2014.

[49] R. K. Suppiah, S. Rajan, J. Paul, and L. Kumar, "Respiratory and hemodynamic outcomes following exchange extubation with laryngeal mask airway as compared to traditional awake extubation," Anesthesia: Essays and Researches, vol. 10, no. 2, pp. 212-217, 2016.

[50] H. N. Ma, H. L. Li, and W. Che, "[Effect of exchange of tracheal tube for laryngeal mask airway (LMA) on intratracheal extubation stress response under deep anesthesia 
level after surgery in elderly patients with hypertension]," Zhonghua Wai Ke Za Zhi, vol. 48, no. 23, pp. 1811-1814, 2010.

[51] B. C. Tsui, A. Wagner, D. Cave, C. Elliott, H. El-Hakim, and S. Malherbe, "The incidence of laryngospasm with a "no touch" extubation technique after tonsillectomy and adenoidectomy," Anesthesia \& Analgesia, vol. 98, no. 2, pp. 327-329, 2004

[52] S. Sheta, E. Nada, and A. Abdelhalim, "Evaluation of "no touch" extubation technique on airway-related complications during emergence from general anesthesia," Saudi Journal of Anaesthesia, vol. 5, no. 2, pp. 125-131, 2011.

[53] F. Peng, M. Wang, H. Yang, X. Yang, and M. Long, "Efficacy of intracuff lidocaine in reducing coughing on tube: a systematic review and meta-analysis," Journal of International Medical Research, vol. 48, no. 2, pp. 030006052090187300060520901872, 2020.

[54] F. Lam, Y.-C. Lin, H.-C. Tsai, T.-L. Chen, K.-W. Tam, and C.-Y. Chen, "Effect of intracuff lidocaine on postoperative sore throat and the emergence phenomenon: a systematic review and meta-analysis of randomized controlled trials," PLoS One, vol. 10, no. 8, Article ID e0136184, 2015.

[55] J. Zamora Lozano, J. A. Cruz Villaseñor, J. Rodríguez Reyes, J. P. Sánchez Rodríguez, G. Briones Corona, and L. A. Gallardo Alonso, "[Comparison of topical, intravenous, and intracuff lidocaine for reducing coughing after extubation during emergence from general anesthesia]," Revista Española de Anestesiología y Reanimación, vol. 54, no. 10, pp. 596-601, 2007.

[56] S. S. Yang, N.-N. Wang, T. Postonogova et al., "Intravenous lidocaine to prevent postoperative airway complications in adults: a systematic review and meta-analysis," British Journal of Anaesthesia, vol. 124, no. 3, pp. 314-323, 2020.

[57] S. N. Swamy and R. Madhusudhana, "Attenuation of hemodynamic responses to endotracheal extubation with different doses of diltiazem with lignocaine: a placebo-controlled study," Anesthesia, Essays and Researches, vol. 12, no. 2, pp. 428-433, 2018.

[58] K. Mikawa, K. Nishina, N. Maekawa, and H. Obara, "Attenuation of cardiovascular responses to tracheal extubation: verapamil versus diltiazem," Anesthesia and Analgesia, vol. 82, no. 6, pp. 1205-1210, 1996.

[59] N. K. Hung, C. T. Wu, S. M. Chan et al., "Effect on postoperative sore throat of spraying the endotracheal tube cuff with benzydamine hydrochloride, $10 \%$ lidocaine, and $2 \%$ lidocaine," Anesthesia and Analgesia, vol. 111, no. 4, pp. 882-886, 2010.

[60] Y.-S. Huang, N.-K. Hung, M.-S. Lee et al., "The effectiveness of benzydamine hydrochloride spraying on the endotracheal tube cuff or oral mucosa for postoperative sore throat," Anesthesia \& Analgesia, vol. 111, no. 4, pp. 1-91, 2010.

[61] B. Lévy, F. Mouillac, D. Quilichini, J. Schmitz, J. Gaudart, and F. Gouin, "[Topical methylprednisolone vs lidocaïne for the prevention of postoperative sore throat]," Annales Françaises d'Anesthésie et de Réanimation, vol. 22, no. 7, pp. 595-599, 2003.

[62] J. Watkins, D. Lee, W. A. White Jr., and S. Mundy, "Effects of topical lidocaine on successful extubation time among patients undergoing elective carotid endarterectomies," AANA Journal, vol. 80, no. 2, pp. 99-104, 2012.

[63] G. Turan, A. Ozgultekin, C. Turan, E. Dincer, and G. Yuksel, "Advantageous effects of dexmedetomidine on haemodynamic and recovery responses during extubation for intracranial surgery," European Journal of Anaesthesiology, vol. 25, no. 10, pp. 816-820, 2008.
[64] S. M. Hadi, A. J. Saleh, Y. Z. Tang, A. Daoud, X. Mei, and W. Ouyang, "The effect of KETODEX on the incidence and severity of emergence agitation in children undergoing adenotonsillectomy using sevoflurane based-anesthesia," International Journal of Pediatric Otorhinolaryngology, vol. 79, no. 5, pp. 671-676, 2015.

[65] G. Dollo, J.-P. Estebe, P. Le Corre, F. Chevanne, C. Ecoffey, and R. Le Verge, "Endotracheal tube cuffs filled with lidocaine as a drug delivery system: in vitro and in vivo investigations," European Journal of Pharmaceutical Sciences, vol. 13, no. 3, pp. 319-323, 2001.

[66] J. M. Sconzo, J. C. Moscicki, and C. A. DiFazio, "In vitro diffusion of lidocaine across endotracheal tube cuffs," $R e$ gional Anesthesia, vol. 15, no. 1, pp. 37-40, 1990.

[67] C.-J. Huang, M.-C. Tsai, C.-T. Chen, C.-R. Cheng, K.-H. Wu, and T.-T. Wei, "In vitro diffusion of lidocaine across endotracheal tube cuffs," Canadian Journal of Anesthesia/Journal Canadien D’anesthésie, vol. 46, no. 1, pp. 82-86, 1999.

[68] B. Salim, S. Rashid, M. A. Ali, A. Raza, and F. A. Khan, "Effect of pharmacological agents administered for attenuating the extubation response on the quality of extubation: a systematic review," Cureus, vol. 11, no. 12, p. e6427, 2019.

[69] B.-F. Lin, D.-T. Ju, C.-H. Cherng et al., "Comparison between intraoperative fentanyl and tramadol to improve quality of emergence," Journal of Neurosurgical Anesthesiology, vol. 24, no. 2, pp. 127-132, 2012.

[70] Z. Benoît, S. Wicky, J. F. Fischer et al., "The effect of increased $\mathrm{FIO}(2)$ before tracheal extubation on postoperative atelectasis," Anesthesia and Analgesia, vol. 95, no. 6, p. 1777, 2002.

[71] U. Nimmagadda, M. R. Salem, and G. J. Crystal, "Preoxygenation," Anesthesia \& Analgesia, vol. 124, no. 2, pp. 507-517, 2017.

[72] S. G. Lindahl and M. Mure, "Dosing oxygen: a tricky matter or a piece of cake?" Anesthesia \& Analgesia, vol. 95, no. 6, pp. 1472-1473, 2002.

[73] H. K. King and K. Lewis, "Guedel oropharyngeal airway does not prevent patient biting on the endotracheal tube," $A n$ aesthesia and Intensive Care, vol. 24, no. 6, pp. 729-730, 1996.

[74] D. Falzon, R. Foye, P. Jefferson, and D. R. Ball, "Extubation guidelines: guedel oropharyngeal airways should not be used as bite blocks," Anaesthesia, vol. 67, no. 8, p. 919, 2012.

[75] C. M. Lee, K. S. Song, B. R. Morgan et al., "Aspiration of an oropharyngeal airway during nasotracheal intubation," The Journal of Trauma, vol. 50, no. 5, pp. 937-938, 2001.

[76] J. Zaltzman and A. Ferman, "An acute life-threatening complication caused by a Guedel airway," Critical Care Medicine, vol. 15, no. 11, p. 1074, 1987.

[77] J. F. Nunn and J. P. Payne, "Hypoxaemia after general anaesthesia," Lancet, vol. 2, no. 7257, pp. 631-632, 1962.

[78] R. W. Morris, A. Buschman, D. L. Warren, J. H. Philip, and D. B. Raemer, "The prevalence of hypoxemia detected by pulse oximetry during recovery from anesthesia," Journal of Clinical Monitoring, vol. 4, no. 1, pp. 16-20, 1988.

[79] I. L. Tyler, B. Tantisira, P. M. Winter, and E. K. Motoyama, "Continuous monitoring of arterial oxygen saturation with pulse oximetry during transfer to the recovery room," $A n$ esthesia and Analgesia, vol. 64, no. 11, pp. 1108-1112, 1985.

[80] I. Blair, R. Holland, W. Lau, N. McCarthy, T. S. Chiah, and D. Ledwidge, "Oxygen saturation during transfer from operating room to recovery after anaesthesia," Anaesthesia and Intensive Care, vol. 15, no. 2, pp. 147-150, 1987.

[81] T. J. Caruso, T. E. Mokhtari, M. J. Coughlan et al., "Pediatric postoperative pulse oximetry monitoring during transport to the postanesthesia care unit reduces frequency of hypoxemia," 
The Joint Commission Journal on Quality and Patient Safety, vol. 43, no. 3, pp. 146-150, 2017.

[82] B. S. Kodali, "Capnography outside the operating rooms," Anesthesiology, vol. 118, no. 1, pp. 192-201, 2013.

[83] A. Maity, S. Maulik, D. Saha, M. Sutradhar, S. Swaika, and B. Choudhury, "Detection of hypoxia in the early postoperative period," Anesthesia: Essays and Researches, vol. 6, no. 1, pp. 34-37, 2012.

[84] R. Jain, N. Sethi, and J. Sood, "Loss of integrity of a reinforced endotracheal tube by patient bite," Indian Journal of Anaesthesia, vol. 57, no. 4, p. 424, 2013.

[85] M. J. Peck and S. M. Needleman, "Reinforced endotracheal tube obstruction," Anesthesia \& Analgesia, vol. 79, no. 1, p. 193, 1994.

[86] C. O. Hoffmann and G. A. Swanson, "Oral reinforced endotracheal tube crushed and perforated from biting," Anesthesia and Analgesia, vol. 69, no. 4, pp. 552-553, 1989.

[87] R. A. McTaggart, A. Shustack, T. Noseworthy, and R. Johnston, "Another cause of obstruction in an armored endotracheal tube," Anesthesiology, vol. 59, no. 2, p. 164, 1983.

[88] J. M. Hull, "Occlusion of armoured tubes," Anaesthesia, vol. 44 , no. 9 , p. $790,1989$.

[89] C. S. Kong, "A small child can bite through an armoured tracheal tube," Anaesthesia, vol. 50, no. 3, p. 263, 1995.

[90] E. H. Liu and P. S. Yih, "Negative pressure pulmonary oedema caused by biting and endotracheal tube occlusion--a case for oropharyngeal airways," Singapore Medical Journal, vol. 40, no. 3, pp. 174-175, 1999.

[91] A. Williams and G. Singh, "Tongue bite injury after use of transcranial electric stimulation motor-evoked potential monitoring," Journal of Anaesthesiology Clinical Pharmacology, vol. 30, no. 3, pp. 439-440, 2014. 